\title{
EARLY CHILDHOOD CARIES
}

\author{
Ana Lucía Seminario, Romana Ivančaková \\ Charles University in Prague, Faculty of Medicine in Hradec Králové: Department of Dentistry
}

Summary: Early childhood caries (ECC) represents a serious problem in pediatric dentistry. Not only because of its rapidity but also because of age of affected children. This has been given different names such as "rampant caries" and "baby bottle syndrome" but now all clinical manifestations have been joined and classified as early childhood caries. The topic of this article is the prevalence, etiology, clinical manifestations and preventive measures of ECC.

Key words: ECC; Streptococcus mutans; Prevention; Bottle Feeding; Caries lesions

\section{Introduction}

Early childhood caries is defined as the presence of one or more decayed (non-cavitated or cavitated lesions), missing (due to caries), or filled tooth surfaces in any primary tooth in a child 36 months of age or younger (6).

Although the prevalence of dental caries has been declined in the last decade due to improvements in dental technology, use of fluoride and better knowledge about prevention of dental caries, unfortunately, many parents underestimate the importance of the first dentition. The primary teeth keep not only the space for the permanent ones but are also necessary for speaking, chewing and appearance, what is important in the self-esteem of the child. In addition, the lesion may cause pain and general health problems.

\section{Prevalence}

The ECC is one of the most common types of caries in infants and toddlers and its prevalence goes from $3.1 \%$ to $53 \%$ in some populations (29). This kind of caries involves especially low socioeconomic groups where the prevalence can reach $90 \%$ of children younger than 3 years (2). Mouradian et al. evaluated the disparities in children's oral health and access to dental care in Seattle (USA). They found that only 1 of 5 children covered by insurance received preventive oral care for which they were eligible and children from low income and minority families had poorer oral health outcomes, fewer dental visits, and fewer protective sealants (19). Petti et al. evaluated the prevalence of ECC in children from 3 to 5 years old in Rome (Italy). They found that the prevalence for any caries was $27.3 \%$ and $7.6 \%$ for ECC (22).

\section{Etiology}

ECC is strongly associated with baby bottle syndrome. The use of feeding bottle or breast as a pacifier keeps the teeth surrounded by liquids, which various bacteria metabolize, producing acids as a waste product. If child's teeth are not regularly cleaned, carious lesion results (4). Nevertheless, recent studies suggest that the etiology of this disease involve more as the kind of drinks which are inside the bottles, time of feeding and its length, previous exposition of any preventive system, etc.

ECC is caused by frequent and prolonged exposure of the tooth to sugar sweetened beverages and the presence of bacteria Streptococcus mutans (S.mutans). These cariogenic bacteria are transmitted from mothers to infants after tooth eruption. S. mutans by itself does not adhere very well to the tooth surface. This requires other plaque forming bacteria for initial colonization. Even when microflora of the lesions in the same child is microbiologically diverse, recent studies indicate that for ECC the major determinant is the physiological behavior of ECC microflora, not its composition (16). The principal source of these bacteria is mother so decreasing mother's S. mutans level may decrease the child's risk of developing ECC (9). It is also important to determine the age when $\mathrm{S}$. mutans colonization starts. Karn explored the relationship between the age and S. mutans invading infants. In all cases, children used baby bottle. They found evidence of S. mutans at 10 months of age. At 12 month of age, $25 \%$ had detectable levels of SM and at 15 months of age, $60 \%$ were colonized (11).

Inappropriate use of baby bottle or breast mainly before bedtime and during the night may destroy primary dentition shortly after eruption. The pattern of the nursing caries change in each individual. The most harmful 
effect has frequent use of baby bottle during the night, when the child sleeps with the bottle in the mouth. During this time the liquid with sugar, stays around the teeth for many hours giving an excellent source of nutrition for oral bacteria. Besides this, the salivary flow is decreased during nighttime which makes oral environment highly cariogenic. The first lesions appear on incisors of upper jaw but when the bottle is used also during the day, caries lesions are present even on labial surfaces of lower incisors.

The highest risk of ECC is when the baby bottle is still used after the first year of age. When children are still allowed to drink sweetened liquids from the bottle, this starts to be a habit. These children may have very inappropriate caloric intake or high fluid intake may cause a rejection of other foods, what leads to an overall poor nutrition outcome. Some young children with ECC may be severely underweight because of associated pain and disinclination to eat. Finally, they have a slower growth compared to caries-free infants (1).

Combination of inappropriate bottle feeding with the bottle content and frequency of feeding significantly increases the risk of ECC. Frequent consumption of liquids containing fermentable carbohydrates (e.g. juice, milk, infant formula and other sweetened beverages) increases the risk of dental caries due to prolonged contact between sugars in the consumed liquid and cariogenic bacteria on the susceptible teeth (6). Many studies have shown that cow's milk has less cariogenic potential than other bottle contents, because lactose is probably not metabolized by oral microflora so easy as other sugars $(5,27)$. The point is associated with the content of the bottle. Many parents add either sucrose or sucrose-containing products to milk or sucrose-containing formula itself. Behrendt et al. studied the relationship between bottle content and nursing caries. Their results confirm the risk of tooth destruction, typical for nursing bottle syndrome, by prolonged and frequent consumption of cariogenic beverages from vessels with billshaped extensions (3).

Mohan and Tinanoff investigated the relationship between bottle usage/content, age, and number of teeth with S. mutans colonization in 6-24-month-old children. They concluded that approximately $20 \%$ of children younger than 14 months of age were infected with S. mutans and that colonization in this sample of low-income preschool children may begin earlier than suggested by other investigators. Additionally, the risk of S. mutans colonization appears to be lower among infants who consume milk rather than sweetened beverages in the bottle (18).

It is evident that ECC involves many important factors. Ramos-Gomez et al. studied the relationship among bacteria, behavior and environmental factors associated with ECC in USA. They found a significant correlation between dental caries in infants, lack of dental insurance of children, family income and the educational level of mother of the child (25).

\section{Clinical manifestation}

The ECC involves many forms of the same disease. The most common is the baby bottle tooth decay (BBTD), which has a typical defined pattern $(6,21)$. The lesions are characterized by a fast progression on smooth surfaces especially in the upper jaw. Upper incisors are first involved. Early clinical manifestation is also evident on first primary molars in both jaws. Because of the eruption sequence, canines and second molars have less opportunity for being affected. It is common that lower incisors do not have lesions because they are protected by the tongue and the lower lip, and because of the proximity of the sublingual salivary glands (10).

The distribution of the lesions is related to the route of the liquid since it comes out of the bottle. The first lesion often appears on the vestibular surface of upper incisors at gingival third of the crown as a white decalcificated spot on enamel surface shortly after the eruption (8). These lesions start to change its color to light yellow and begin to extend laterally to proximal surfaces. In severe stage, the proximal lesions can join producing pathological fractures of the crown in the presence of a slight trauma (Fig.1).

The other common form of ECC is rampant caries. This caries affects almost all primary teeth even the lower incisors without specific pattern and is related to the systemic problems as agenesis of salivary glands, diabetes, irradiation, etc (24). Enamel hypoplasia is a deficient enamel matrix formation during the teeth development, which could be observed as trenches or spots, or as a partial or complete loss of enamel. Unlike ECC, hypoplasia follows the enamel pattern's formation (from the incisal to gingival third), whereas ECC lesion starts on the smooth surface in the gingival third of the crown with almost no contact to the incisal edge (except in severe cases). Hypoplasia is usually symmetric and is evident immediately after the tooth eruption. In many cases, this defect is related to systemic alterations.

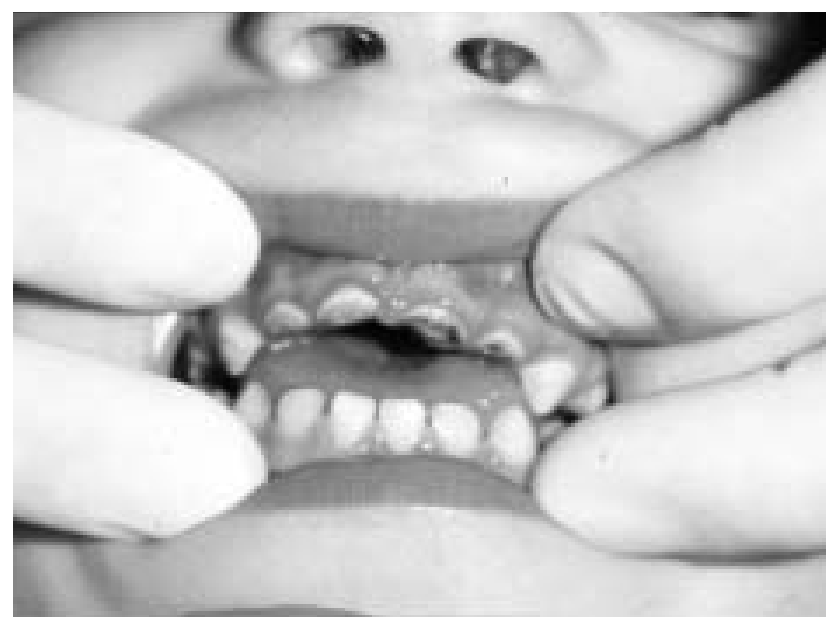

Fig. 1: Severe form of early childhood caries. 


\section{Treatment}

Because of the aggressive nature of ECC, treatment should be definitive and specific for each individual patient. Very early detection of enamel demineralization is detrimental for successful treatment. Chalky white spots or lines may remineralize after fluoride treatment and diet modification. Proper oral hygiene in term of regular removal of dental plaque is necessary condition. However, when evident cavitation is found, conventional restorative treatment may not arrest the disease. Due to areas of decalcification and hypoplasia, rapid cavitations can develop. The use of fluoride therapy may be necessary to reduce the risk of development and progression of caries (6). Alternative restorative treatment techniques, using materials such as fluoride releasing glass-ionomer cements, hold promise as both preventive and therapeutic approaches (9). Aggressive therapy, including the placement of stainless steel crowns, may be necessary to arrest the carious process. Stainless steel crowns, mainly on primary molars, decrease the number of tooth surfaces at risk for new or secondary caries, and are less likely than other restorations to require re-treatment (26).

\section{Prevention}

Parents should be sufficiently informed about the risk of ECC and its complications. Prevention regimens have met with mixed success where they have been implemented as public health programs, regardless of the socio-economic status of the children's parents. ECC involves not only teeth, but consequences of this disease may lead to more widespread health issues (9).

Prevention starts in pre-natal and peri-natal periods. Women should be advised to optimize nutrition during the third trimester and the infant's first year, when enamel is undergoing maturation. Hypoplasia is common in children with low birth weight or systemic illness in the neonatal period $(6,9)$. There is considerable presumptive evidence that malnutrition/undernutrition during the perinatal period may cause hypoplasia $(6,9)$. The child with hypoplasia and without dental care has a high risk to develop a severe case of ECC (17).

Studies of bacterial DNA have suggested that mother is the primary channel of transmission of S. mutans to the infant (14). For that, conscientious tooth brushing, flossing and use of an antibacterial mouth rinses, e.g. one containing chlorhexidine gluconate are critically important in keeping the levels of S. mutans in the parent's saliva below the effective transmissibility threshold, particularly during the time when the child's teeth are emerging. Many studies have reported antimicrobial therapy in the prevention of ECC with good results. Lopez et al. studied the efficacy of iodine povidone as an antimicrobial agent in children between 12 to 19 months years old. They concluded that topical antimicrobial therapy increased disease-free survival in children at high risk for ECC (15).
Regular tooth brushing, at least twice a day after feeding, will also have a significant impact to the child's susceptibility to early childhood caries. Tooth cleaning with sterile gauze between the fingers (or with special dental finger costs which are now available) and the use of small amount of fluoride-containing dentifrice will clear away colonies of micro-organisms and will make fluoride available to the child's salivary mineral solution to facilitate remineralisation of any early lesions.

In addition, an adequate use of bottle, as an instrument of feeding not as a pacifier, decreases considerably ECC. Ollila et al. have confirmed, after 2 years of pursuit that the prolonged pacifier sucking and use of nursing bottle at night are risk factors for dental caries in children (20). Similarly, Schwartz et al. found that children who felt asleep while feeding from the bottle had significantly more cases of „nursing caries“ than did children who discarded the bottle before falling asleep (28).

Primary care physicians can play an important role in prevention, detection and control of ECC. In many cases, they are the first who have contact with the child and mother. Pierce et al. made and interesting study where evaluated the accuracy of pediatric primary care providers, screening and referral for ECC. They concluded that after 2 hours of training in infant oral health, primary care providers achieved an adequate level of accuracy in identifying children with cavitated carious lesions. They also suggested that dental screening can easily be incorporated into a pediatrics practice for a referral when it is necessary (23).

The American Academy of Pediatric Dentistry (AAPD) has given preventive measures that include either ECC or Infant Oral Health Care $(6,7)$ :

1. Infant oral health care begins ideally with prenatal oral health counseling for parents.

2. An oral health consultation visit within six months of eruption of the first tooth, and no later than 12 months of age, is recommended to educate parents and provide anticipatory guidance for prevention of dental disease.

3. At the infant oral evaluation visit, the dentist should:

a) Record a thorough medical and dental history, covering the prenatal, perinatal, and postnatal periods.

b) Complete a thorough oral examination.

c) Assess the patient's risk of developing oral and dental disease, and determine an appropriate prevention plan and interval for periodic reevaluation based on that assessment.

d) Discuss and provide anticipatory guidance regarding dental and oral development, fluoride status, nonnutritive oral habits, injury prevention, oral hygiene, and effects or diet on the dentition.

4. Infants should not be put to sleep with a bottle. Ad libitum nocturnal breast-feeding should be avoided after the first primary tooth begins to erupt.

5. Parents should be encouraged to have infants drink from a cup as they approach their first birthday. Infants should be weaned from the bottle at 12-14 months of age. 
6. Consumption of juices from a bottle should be avoided. When juices are offered, it should be from a cup.

7. Oral hygiene measures should be implemented by the time of eruption of the first primary tooth.

8. An attempt should be made to assess and decrease the mother's/primary caregiver's mutans streptococci levels to decrease the transmission of cariogenic bacteria and lessen the child's risk of developing ECC.

9. Dentists who perform such services for infants should be prepared to provide therapy when indicated, or should refer the patient to an appropriately trained individual for necessary treatment.

\section{Conclusion}

Despite of many caries preventive measures, which have been introduced in the past decades, ECC attacks a high percentage of young children. In countries with evident socio-economic differences, ECC can be seen, especially, between families in low levels.

The reduction of ECC depends not only on the professionals but also on the family where mother plays the main role.

Close cooperation with pediatricians might improve the early detection of this disease.

\section{References}

1. Ahyan, H., E. Suskan, S. Yildirim. The effect of nursing or rampant caries in height, body weight and head circumference. Journal of Clinical Paediatric Dentistry 2000; 20(3): 209-212.

2. Arthur J. Nowak. Rationale for timing of the first oral evaluation. Paediatric Dentistry 1999; 19(1): 8-11.

3. Behrendt A, Sziegoleit F, Muler-Lessmann V, Ipek-Ozdemir G, Wetzel WE. Nursing-bottle syndrome caused by prolonged drinking from vessels with bill-shaped extensions. ASDC J Dent Child Jan-Feb2001; 68(1):47-50.

4. Berkowitz, R. Aetiology of nursing caries: A microbiologic perspective. Journal of Public Health Dentistry 2000; 56(1): 51-4.

5. Bowen, W H. and S.K. Pearson. Effect of milk on cariogenesis. Caries Research 1993; 27:461-466.

6. Clinical Guideline on Baby Tooth Decay/Early Childhood Caries/Breast feeding/Early Childhood Caries: Unique Challenges and Treatment Options. Reference Manual, AAPD, 2001-2002.

7. Clinical Guideline on Infant Oral Health Care. AAPD, Reference Manual, 2000-2001

8. Dimitrova MM, Kukleva MP, Kondeva VK. Prevalence of early childhood caries and risk factors in children from 1 to 3 years of age in Plovdiv, Bulgaria. Folia Med (Plovdiv) 2000; 42(3):50-4

9. Drury TF, Horowitz AM, Ismail AI, Haertens MP, Rozier RG, Selwitz RH Diagnosis and Reporting Early Childhood Caries Research Purposes. J of Public Health Dent 1999; 59: 192-7.
10. Gelbier MJ, Winter GB. Absence of salivary glands in children with rampant dental caries: report of seven cases. Int J Paediatr Dent Dec 1995;5(4):253-7.

11. Karn TA, O'Sullivan DM, Tinanoff N. Colonization of mutans streptococci in 8-to 15-month-old children. J Public Health Dent 1998; 58(3):248-9.

12. Kukletová M, Svobodová M, Kuklová J. Vliv výživových návyků na kazivost chrupu malých dětí. Prakt Zub Lék 2000;48:75-81.

13. Lekešová I, Šalandová M, Rokytová K. Kazivost dočasného chrupu dvouletých dětí v Praze 6. Prakt Zub Lék 1994;42:35-40.

14. Li Y, Caufield P.W. The fidelity of initial acquisition of mutans streptococci by in fants from their mothers. Journal of Dental Research 1995; 74 (2): 681-5.

15. Lopez L, Berkowitz R, Spiekerman C, Weinstein P. Topical antimicrobial therapy in the prevention of early childhood caries: a follow-up report. Pediatr Dent 2000; May-Jun 24(3): 204-6.

16. Marchant S, Brailsford S.R., Twomey A.C., Roberts G.J. and Beighton D. The predominant microflora of nursing caries lesions. Caries Res 2001; 35: 397-406.

17. Matee M, van't Hof M, Maselle S, Mikx F, van Palenstein Helderman W. Nursing caries, linear hypoplasia, and nursing and weaning habits in Tanzanian infants. Community Dent Oral Epidemiol 1994; Oct 22:289-93.

18. Mohan A, Morse DE, O'Sullivan DM, Tinanoff N. The relationship between bottle usage/content, age, and number of teeth with mutans streptococci colonization in 6-24-month-old children. Community Dent Oral Epidemiol Feb1998; 26(1):12-20.

19. Mouradian WE, Wehr E, Crall JJ. Disparities in children's oral health and access to dental care. JAMA 2000; Nov 22-29; 284(20): 2625-31.

20. Ollila P, Niemela M, Uhari M, Larmas M. Prolonged pacifier-sucking and use of a nursing bottle at night: possible risk factors for dental caries in children. Acta Odontol Scand 1998; Aug56(4):233-7.

21. Ostos MJ, González E, Menéndez M. Patrones de caries dental en el nińo preescolar. Odontología Pediátrica1992; 1:171-181.

22. Petti S, Cairella G, Tarsitani G. Rampant early childhood dental decay: an example from Italy. J Public Health Dent 2000; 60 (3): 159-66.

23. Pierce KM, Rozier RG, Vann WF Jr. Accuracy of pediatric primary care providers' screening and referral for early childhood caries. Pediatrics 2002; May 109(5):E82-2.

24. Pinkham, J.R., et al, eds. Pediatric dentistry: infancy through adolescence. $2^{\text {nd }}$ ed. Philadelphia: Saunders, 1994.

25. Ramos-Gomez FJ, Weintraub JA, Gansky SA, Hoover CI, Featherstone JD. Bacterial, behavioral and environmental factors associated with early childhood caries. J Clin Pediatr Dent 2002; 26(2):165-73.

26. Randall RC, Vrijhoef MMA, Wilson NHF. Efficacy of Preformed Metal Crowns vs. Amalgam Restorations in Primary Molars: A Systematic Review. JADA 2000; $131,337-43$

27. Reynolds, E.0C., PE Riley, E. Storey, Phosphoprotein inhibition of hydroxyapatita dissolution. Calcif Tiss Int 1982; 34:52-56 (supplement).

28. Schwartz SS, Rosivack RG, Michelotti P. A child's sleeping habit as a cause of nursing caries. ASDC J Dent Child 1993; Jan-Feb 60(1):22-5.

29. Yiu CK and Wei SHY Management of rampant caries in children. Quitessence International 1992; 23(3): 159-168.

Submitted January 2003.

Accepted May 2003.

Ana Lucía Seminario Antúnez de Mayolo, DDS, MDS, University Hospital in Hradec Králové, Department of Dentistry, 50005 Hradec Králové, Czech Republic. e-mail: anase@hotmail.com 